\title{
Induction of Extracellular Matrix Glycoproteins in Brassica Petioles by Wounding and in Response to Xanthomonas campestris
}

\author{
Huw A. Davies, Michael J. Daniels, and J. Maxwell Dow \\ The Sainsbury Laboratory, John Innes Centre, Colney Lane, Norwich, NR4 7UH, U.K. \\ Received 10 February 1997. Accepted 31 May 1997.
}

\begin{abstract}
A panel of monoclonal antibodies that recognize plant extracellular matrix glycoproteins previously implicated in plant-microbe interactions was used to study the effects of pathogen inoculation and wounding on glycoproteins in petioles of Brassica campestris. The panel of monoclonals comprised two sets: JIM11, JIM12, and JIM20 recognize epitopes carried on hydroxyproline-rich glycoproteins (HRGPs) (M. Smallwood, A. Beven, N. Donovan, S. J. Neill, J. Peart, K. Roberts, and J. P. Knox, Plant J. 5:237246, 1994); MAC204 and MAC265 recognize glycoproteins of the Rhizobium infection thread (K. A. VandenBosch, D. J. Bradley, S. Perotto, G. W. Butcher, and N. J. Brewin, EMBO J. 8:335-342, 1989). Wounding or inoculation of petioles with avirulent strains of pathovars of Xanthomonas campestris induced the synthesis of two new groups of antigens: gp160 ran as a smear on sodium dodecyl sulfatepolyacrylamide gel electrophoresis (SDS-PAGE) with apparent molecular mass from 120 to $200 \mathrm{kDa}$ and was recognized by JIM20 and MAC204; gpS remained in the stacking gel on SDS-PAGE and was recognized by JIM11, JIM20, and MAC204. The response to virulent strains of pathovars of $X$. campestris was either less pronounced or absent. gpS comprised several components that were resolved by cation-exchange chromatography. Some of these components were characterized as extensin-like HRGPs. The level of induction of the gpS group of antigens by virulent strains was not altered by mutation of a number of genes required for basic pathogenicity or by heat-killing the bacteria.
\end{abstract}

Additional keywords: immunoanalysis, tissue printing, Western blotting.

We are interested in the role that glycoproteins of the plant extracellular matrix may play in the defense of plants against phytopathogens. We have a particular interest in the interaction between brassicas and Xanthomonas campestris pv. campestris, the causal agent of bacterial black rot of crucifers (Williams 1980). X. campestris pv. campestris is a vascular pathogen that attacks the aerial plant parts. The bacteria normally enter leaves through hydathodes at the leaf margin but

Corresponding author: J. M. Dow; The Sainsbury Laboratory, John Innes Centre, Colney Lane, Norwich NR4 7UH; Telephone: 01603452 571; Fax: 01603250 024; E-mail: dowm@bbsrc.ac.uk can enter through wounds in other parts of the plant (Cook et al. 1952). Wound inoculation of the petioles is a convenient method for consistent reproduction of black rot symptoms in compatible interactions of brassicas with X. campestris pv. campestris (Shaw and Kado 1988). In incompatible interactions with other pathovars of $X$. campestris, petioles often develop necrosis with subsequent splitting of the petiole tissue at the site of wound inoculation (Kamoun et al. 1992). These differential interactions have prompted us to use the petioles of turnip (Brassica campestris) to study plant responses to bacteria.

We have concentrated on a subset of the plant extracellular matrix glycoproteins that are identified by a panel of monoclonal antibodies that recognize antigens previously implicated in plant-microbe interactions. This panel of monoclonal antibodies comprises two sets: the first set, consisting of MAC204 and MAC265, which were generated with preparations from Rhizobium-induced pea nodules as immunogens (VandenBosch et al. 1989), recognize (as yet uncharacterized) glycoproteins in the lumen of the Rhizobium infection thread. In addition, MAC265 recognizes proline-rich proteins (PRPs) involved in the rapid cross-linking response in soybean suspension cells to elicitors and pathogens (Bradley et al. 1992; Brisson et al. 1994) and a stress-induced glycoprotein in bean capable of binding to fungal pathogens (Millar et al. 1992). The precise nature of the epitope recognized by MAC265 is not known. MAC204 recognizes a periodate-sensitive epitope that is present on tomato extensin (Davies 1996). The second set of antibodies (JIM11, JIM12, and JIM20) recognize epitopes carried on, but not necessarily restricted to, hydroxyproline-rich glycoproteins (HRGPs) (Smallwood et al. 1994). It has been suggested that the JIM11 and JIM20 antibodies recognize specific arabinosylation patterns of HRGPs whereas JIM12 may recognize a protein epitope or a nonterminal oligosaccharide structure (Smallwood et al. 1994). A body of work has implicated HRGPs in plant defense against pathogen attack and as a response to wounding (reviewed by Bowles 1990). Increased synthesis and cross-linking of HRGPs such as extensin may lead to strengthening of the cell wall to localize pathogens or isolate wounded tissue (Esquerré-Tugayé et al. 1979; Showalter et al. 1985). Agglutination and hence immobilization of phytopathogenic bacteria by cell surface HRGPs may also contribute to plant defense (Leach et al. 1982; Mellon and Helgeson 1982; Swords and Staehelin 1993). 
In previous work we used this panel of monoclonal antibodies to identify two glycoproteins (gp45 and gp120) present in unwounded healthy petioles (Davies et al. 1997). gp120 was largely associated with the vascular bundle whereas gp45 was present in the pith tissue. Here we report the effects of wounding and of the inoculation of petioles with different pathovars of $X$. campestris (in the absence of wounding) on the levels and complement of glycoprotein antigens. This was assessed by tissue printing of petioles and Western blotting (immunoblotting) of petiole extracts. We have found that both wounding and inoculation with avirulent bacteria (an incompatible interaction) caused an induction of new antigens with accompanying changes in the levels of gp45. In contrast, antigen induction in compatible interactions was either much less pronounced or absent. A subgroup of the induced antigens that were specifically recognized by JIM11 were characterized as extensin-like HRGPs.

We extended the studies on the bacterial induction of HRGPs to investigate the effects on induction of mutation of a number of genes previously implicated in the pathogenicity of $X$. campestris. It has been suggested that at least a subset of genes required for basic pathogenicity in bacteria function to suppress the induction of defense responses in plants or in the biosynthesis of surface components that mask bacteria, preventing recognition by plants (Jakobek et al. 1993; Kamoun et al. 1992; Palva et al. 1993; Newman et al. 1994; Brown et al. 1995). These genes include those of the hrp gene cluster (for hypersensitive resistance and pathogenicity), which are present in most if not all plant-pathogenic bacteria, genes encoding the biosynthesis of extracellular or cell surface polysaccharides, the $h r p X$ gene of $X$. campestris, and genes encoding certain extracellular enzymes. The existence of an active suppression of the induction of the glycoproteins in compatible interactions was also investigated by inoculation of petioles with heat-killed bacteria. The results indicate that, in compatible interactions, bacteria do not suppress the induction of extensin-like glycoproteins in Brassica campestris but that many bacteria, including Escherichia coli, can induce a low-level response by a mechanism not requiring living organisms.

\section{RESULTS}

\section{Glycoprotein antigens in petioles subjected to wounding stress.}

The effects of different forms of wound stress on the pattern of glycoproteins in petioles were initially assessed by Western blotting of soluble extracts made in Tris-sodium dodecyl sulfate (SDS) buffer. The different forms of stress applied were detachment of the leaf and mechanical wounding of the attached leaf by incision or crushing (see Materials and Methods).

Extracts from unstressed petioles contained the previously described antigens gp45 and gp120 (Davies et al. 1997), which have apparent molecular masses of 120 and $45 \mathrm{kDa}$, respectively, and are both recognized by MAC204, JIM12, and JIM20 (Fig. 1). Detachment of the leaf from the plant resulted in the induction after $24 \mathrm{~h}$ of MAC204 antigens with mobilities different from those observed in extracts from unstressed tissues. The stress-induced glycoproteins detected by MAC204 were assigned to two main groups: antigens with apparent molecular mass from 120 to $200 \mathrm{kDa}$, termed collectively gp160, and antigens termed gpS that were not resolved by SDS-polyacrylamide gel electrophoresis (PAGE) and that remained in the stacking gel. JIM20 reacted with both gp160 and with antigens in the stacking gel and JIM11 reacted specifically with antigens in the stacking gel. JIM12 did not react with gp160 or gpS on a Western blot but it did recognize a new stress-inducible antigen of apparent molecular mass of 80 $\mathrm{kDa}$. In some experiments, induction of gp45 in response to detachment was seen. MAC265 did not recognize any antigen on Western blots of either stressed or unstressed petioles (data not shown).

Vascular bundle and pith tissues were dissected from the petioles of unstressed and detached leaves. Extracts of these dissected tissues were made and subjected to Western analysis with MAC204. The gp120 antigen of unstressed petioles comprises a doublet of bands (Davies et al. 1997). The pith tissue contained only the lower band of this doublet (Fig. 2). The group of antigens termed gp160 were induced mainly in the pith with a small induction in the vascular bundle. The

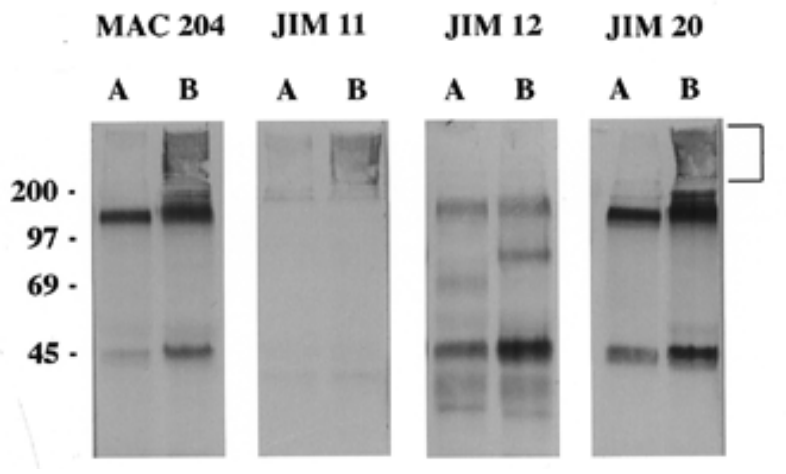

Fig. 1. Western blot (immunoblot) analysis of extracts from unstressed petioles and petioles from leaves stressed by detachment. Western blots were probed with MAC204, JIM11, JIM12, or JIM20. Lane A: unstressed (healthy) petiole; lane B: petioles from leaves $24 \mathrm{~h}$ after detachment. Molecular mass standards (in kilodaltons) are given on left. Position of the stacking gel is indicated on the right by brackets.

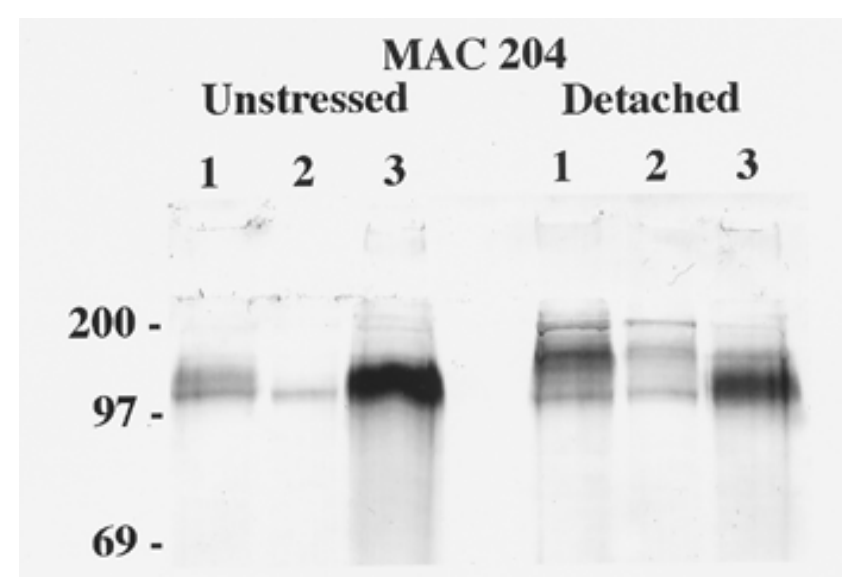

Fig. 2. Western blot (immunoblot) analysis of extracts from different tissues dissected from unstressed petioles and petioles from leaves stressed by detachment. Western blot was probed with MAC204. Lanes 1: whole petiole; lanes 2: pith; lanes 3: vascular bundle. Only top part of the blot is shown. Molecular mass standards (in kilodaltons) are given on left. 
gpS group of antigens, which is specifically recognized by JIM11, was induced in all tissues analyzed from the stressed petiole (not shown). Increases in antigen level occurred throughout the petiole of the detached leaf; immunoanalysis of sections taken from different positions along a $20-\mathrm{cm}$ length of the same detached petiole all showed a dramatic increase in the level of antigen.

The effects of local damage on petioles still attached to the plant were assessed after wounding by making lateral incisions with a scalpel or crushing with forceps. In both cases, the pattern of antigens at the wound site as revealed by Western analysis was essentially the same as seen in leaves stressed by detachment. However, analysis of tissue $2 \mathrm{~cm}$ above or below the wound site showed no differences from unwounded tissue. Hence, the effects of these wounding regimes on antigen induction were highly localized.

The results of this immunoanalysis of stressed plants suggested that the monoclonal antibodies MAC204 and JIM11 would be most useful in studies of plant responses to bacterial challenge since MAC204 recognized all the antigens of interest and JIM11 recognized a subset that were induced by stress.

\section{Glycoprotein antigens in petioles inoculated with phytopathogenic and other bacteria.}

The substantial effects of wounding alone on the induction of antigens precluded the use of wound inoculation in studying those responses of petioles specifically induced by bacteria. As an alternative, bacteria were introduced into petioles by inoculation of aqueous suspensions into the adjoining leaf lamina tissue as described in Materials and Methods. This allowed the introduction of approximately $10^{7} \mathrm{CFU}$ per $\mathrm{cm}$ of length of the petiole without wounding. The bacterial strains used in these studies and their relevant characteristics are described in Table 1. Initial experiments were done with $X$. campestris pv. campestris strain 8004 and $X$. campestris pv. raphani strain 1946. When stab inoculated into petioles, X. cam-

Table 1. Bacterial strains used in this study

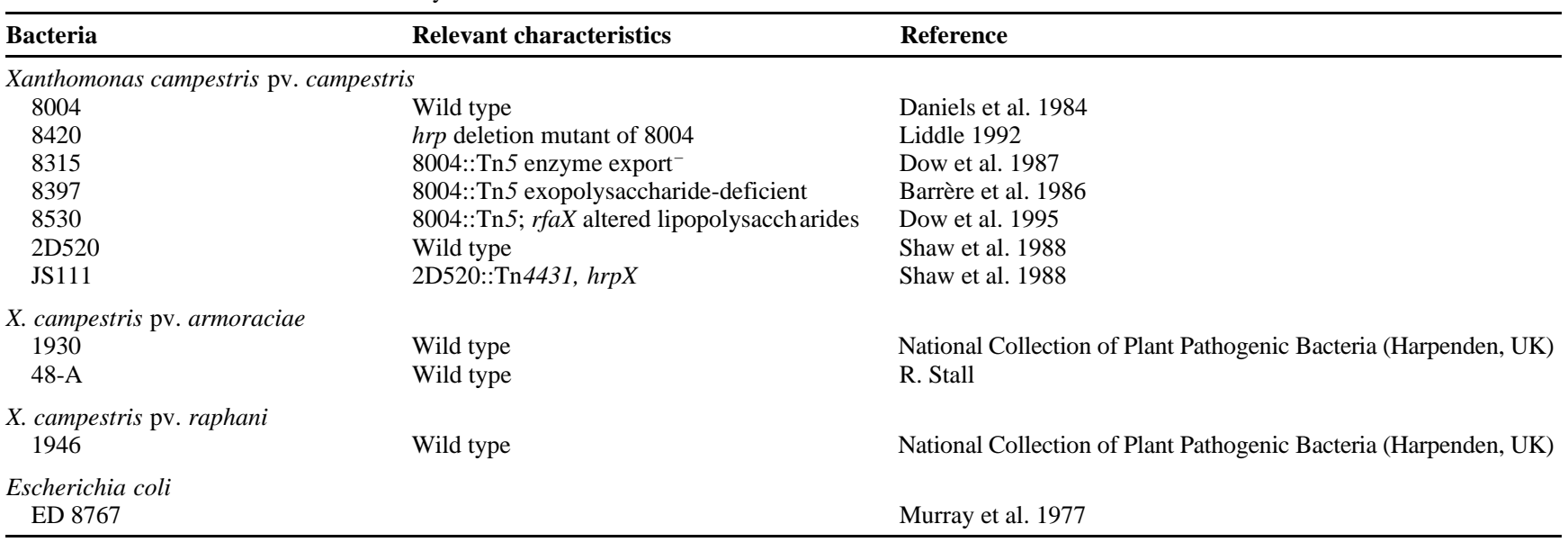

MAC 204

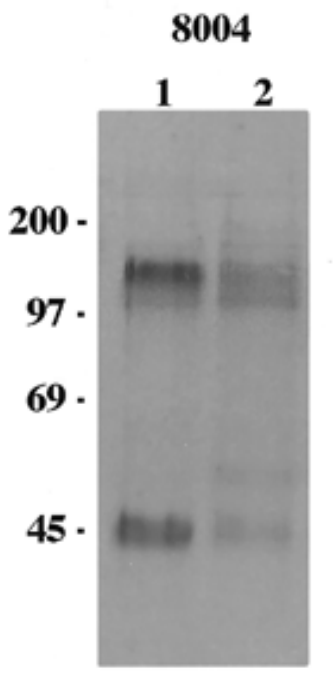

1946

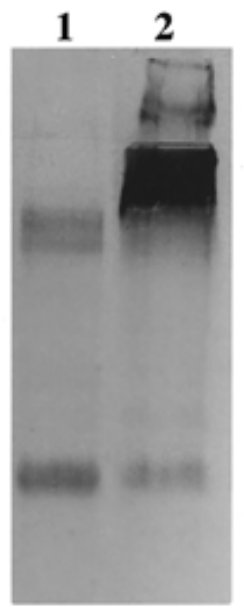

JIM 11

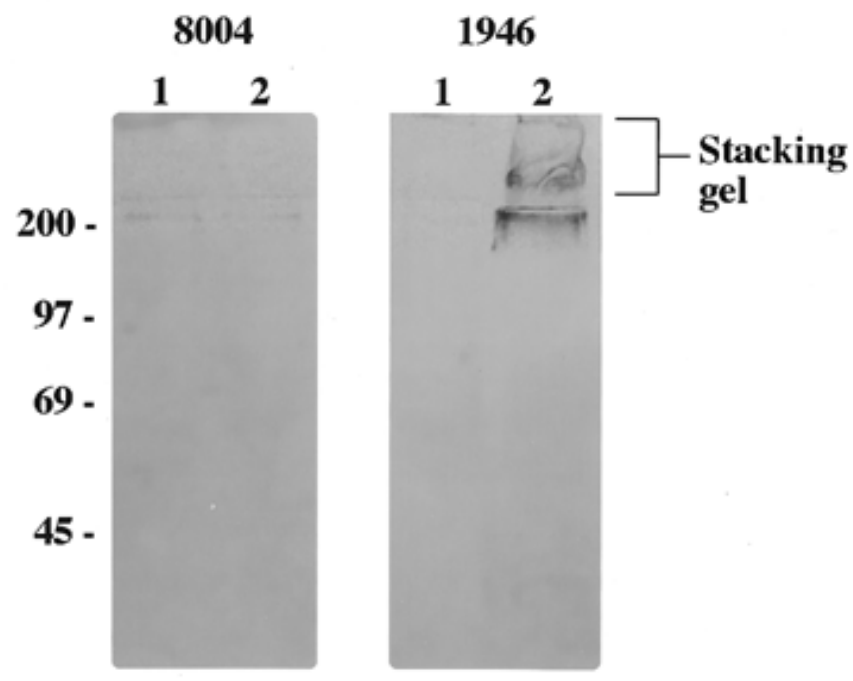

Fig. 3. Western blot (immunoblot) analysis of extracts from unstressed petioles and from petioles 24 h after inoculation with Xanthomonas campestris pv. campestris strain 8004 (a compatible interaction) or X. campestris pv. raphani strain 1946 (an incompatible interaction). Western blots were probed with MAC204 or JIM11. Lane 1: uninoculated; lane 2: $24 \mathrm{~h}$ after inoculation. Molecular mass standards (in kilodaltons) are given on left. 
pestris pv. raphani strain 1946 produced a strong splitting response after 3 to 4 days, indicative of an incompatible interaction (Kamoun et al. 1992). In contrast, no such response was seen with $X$. campestris pv. campestris strain 8004 , indicative of a compatible interaction. These bacterial strains were introduced into petioles via the leaf lamina. Western blots of extracts from petioles inoculated with water alone showed that no changes in antigens were induced by the inoculation procedure. Western blotting of extracts from the bacterially inoculated petioles made $24 \mathrm{~h}$ after inoculation and probed with MAC204 revealed a large induction of antigen in the incompatible but not the compatible interaction (Fig. 3). The induced antigens recognized by MAC204 had gel mobilities similar to those of the antigens gp160 and gpS induced following the stress of detachment of the leaf. The specific induction of gpS in the incompatible interaction was confirmed when replicate Westerns were probed with JIM11, which appears to be specific for gpS. Reductions in the levels of gp45 were apparent, particularly in the compatible interaction.

Tissue prints of infected petioles were probed with MAC204 and JIM11. Both antibodies detected a substantial induction of antigen in the incompatible interaction that was largely associated with the pith tissue and was localized to the site of bacterial inoculation; the results with JIM11 are shown in Figure 4. The distribution and level of antigen in tissue prints of the petiole in the compatible interaction were comparable to those of an uninoculated petiole. In both of these latter cases, labeling with JIM11 was largely restricted to the vascular bundle; the phloem and sclerid fibers were the areas labeled (Davies 1996). Tissue prints were made at different times after inoculation in both compatible and incompatible interactions. In the incompatible interaction, induction of antigen appeared maximal at $24 \mathrm{~h}$ with no effects seen at $8 \mathrm{~h}$ after inoculation. In the compatible interaction, no differences were apparent between tissue prints made at $8,24,48$, and $72 \mathrm{~h}$ after inoculation, and uninoculated petioles. Immunodevelopment of tissue prints with MAC265 did not generate a signal, indicating the absence of both nonspecific binding of the antibodies and endogenous plant alkaline phosphatase activity (the secondary antibody used in immunodevelopment is conjugated to alkaline phosphatase).

Several other strains of $X$. campestris and the unrelated organism $E$. coli were tested for their compatibility with turnip cv. Just Right (by the petiole splitting response after stab inoculation) and for the induction of JIM11 antigens as assessed by tissue printing. Representative tissue prints are also shown in Figure 4. X. campestris pv. campestris strain 2D520 and $X$. campestris pv. armoraciae strain 48-A, which did not cause petiole splitting, induced a low level of JIM11 antigens. $X$. campestris pv. armoraciae strain 1930, which produced a petiole splitting response that was less severe than that caused by $X$. campestris pv. raphani strain 1946, caused a substantial induction of JIM11 antigens. E. coli caused no petiole splitting and a level of response similar to that seen with $X$. campestris pv. campestris 2D520. These experiments with different bacterial strains were performed in triplicate and the whole experiment was repeated with essentially the same result.

\section{Induction of JIM11 antigens in response to heat-killed bacteria.}

Several laboratories have suggested that bacteria in com- patible interactions suppress the induction of defense responses to allow infection. (Jakobek et al. 1993; Kamoun et al. 1992; Palva et al. 1993; Brown et al. 1995). We reasoned that if the low level of induction of JIM11 antigens in response to virulent bacteria was due to a suppression requiring metabolically active bacteria, then dead bacteria might give elevated levels of induction. To test this hypothesis, bacteria were killed by heat treatment before inoculation into the petioles. No appreciable differences were seen in the levels of antigens induced by heat-killed $X$. campestris pv. campestris strains 8004 and 2D520 and the cognate live organisms. In contrast, the level of antigen induced by heat-killed X. campestris pv. raphani strain 1946 (an avirulent strain) was markedly reduced compared with the level seen in response to heatkilled X. campestris pv. campestris strain 2D520.

\section{Effects of mutation of different pathogenicity genes on the response to $X$. campestris.}

The availability of a range of mutants of $X$. campestris pv. campestris strain 8004 carrying lesions in genes required for pathogenicity allowed a test of whether particular bacterial products or processes act to suppress the induction of antigens in the compatible interaction. Accordingly, the response of petioles to bacteria with mutations or deletions of the hrp genes, genes involved in extracellular enzyme export, the biosynthesis of the extracellular polysaccharide xanthan or the outer core of lipopolysaccharide (see Table 1) was assessed by tissue printing. None of these mutants gave a response that was different from that of the wild type. In addition, JS111, an hrpX mutant of $X$. campestris pv. campestris strain 2D520, was tested. HrpX has been implicated in the suppression of defense responses in Brassica campestris seedlings (Kamoun et al. 1992); $h r p X$ mutants induce a necrotic response in seedlings of certain turnip cultivars in which the wild type gave no response. Strain JS111 gave no response in petioles of the turnip cv. Just Right, just as the wild type parent did. There was also no significant difference between these two strains in the level of JIM11 or MAC204 antigen induction.

Table 2. Amino acid composition of glycoproteins from stressed Brassica petioles

\begin{tabular}{lrrrr}
\hline & \multicolumn{4}{c}{ mol\% } \\
\cline { 2 - 5 } Amino acid & gpS & gpS-1 & gpS-2 & gpS-3 \\
\hline Asx & 7.9 & 9.8 & 8.6 & 4.0 \\
Hyp & 8.6 & 5.2 & 4.0 & 19.8 \\
Thr & 9.8 & 6.8 & 7.6 & 5.3 \\
Ser & 11.7 & 12.6 & 15.4 & 13.9 \\
Glx & 8.1 & 8.7 & 11.6 & 5.7 \\
Pro & 4.7 & 5.5 & 5.9 & 3.8 \\
Gly & 8.1 & 10.1 & 12.6 & 4.7 \\
Ala & 9.7 & 9.9 & 7.6 & 4.0 \\
Val & 5.8 & 6.7 & 5.2 & 7.2 \\
Cys & 0.5 & 0.6 & ND & ND \\
Ile & 2.7 & 3.4 & 3.7 & 1.6 \\
Leu & 6.0 & 7.5 & 5.0 & 2.9 \\
Tyr & 3.5 & 2.5 & 2.9 & 9.4 \\
Phe & 2.7 & 2.7 & 2.2 & 1.5 \\
Lys & 6.8 & 6.4 & 3.1 & 9.1 \\
His & 2.8 & 1.6 & 1.1 & 5.1 \\
Arg & 0.6 & ND & 3.5 & 2.0 \\
Met & ND & ND & ND & ND \\
Trp & ND & ND & ND & ND \\
\hline Tryyyy
\end{tabular}

a Not detected. 
The JIM11 epitope is carried on diverse glycoproteins.

The gpS group of antigens could be extracted from petioles from detached leaves with $100 \mathrm{mM}$ Tris- $\mathrm{HCl} \mathrm{pH}$ 8.5. This extract was fractionated as described in Materials and Methods; fractions were assayed with JIM11 to detect gpS. The gpS antigens were soluble in 5\% trichloroacetic acid (TCA). The TCA-soluble material was subjected to size-exclusion chromatography on Sephacryl S400-HR. The major peak of JIM11 reactive material eluted between blue dextran and the previously characterized glycoprotein gp120. These fractions were pooled to give the crude gpS preparation. Amino acid analysis of gpS (Table 2) showed the presence of hydroxyproline (8.6 $\mathrm{mol} \%$ ) with higher levels of serine and threonine (11.7 and 9.8 mol\%, respectively).

Cation exchange chromatography on Bio-Rex 70 at $\mathrm{pH} 8$ resolved gpS into three subfractions as detected by absorbance at $254 \mathrm{~nm}$ : gpS-1 did not bind to the column; gpS-2 eluted between 0.01 and $0.1 \mathrm{M}$ salt; and gpS-3 eluted between 0.25 and $0.7 \mathrm{M}$ salt (Fig. 5A). The elution of JIM11 antigen from the column corresponded with these peaks of absorbance at $254 \mathrm{~nm}$ (Fig. 5B). All three fractions were subjected to SDSPAGE and silver staining. No bands were seen in the resolving gel in any fraction. On Western analysis of these fractions with MAC204, no immunoreactive components were seen in the resolving gel, although antigens that remained in the stacking gel were detected. This showed that the fractions were not contaminated with gp160 or gp120. Amino acid analyses of the gpS-1, gpS-2, and gpS-3 fractions are shown in Table 2. The gpS-3 fraction was particularly rich in hydroxyproline $(19.8 \mathrm{~mol} \%)$ and serine $(13.9 \mathrm{~mol} \%)$ with sub- stantial levels of tyrosine $(9.4 \mathrm{~mol} \%)$ and lysine $(9.1 \mathrm{~mol} \%)$. In contrast, the gpS-1 and gpS-2 fractions had much lower levels of hydroxyproline (4.0 or $5.2 \mathrm{~mol} \%$, respectively) but were both rich in serine and glycine. Monosaccharide analyses of the fractions gpS-1, gpS-2, and gpS-3 are shown in Table 3. Arabinose was the most abundant sugar in all three fractions, constituting more than $90 \mathrm{~mol} \%$ in both gpS-2 and gpS-3 fractions and $60 \mathrm{~mol} \%$ in gpS-1. The other major monosaccharides in gpS-1 were xylose and galactose, which were present in approximately equal levels. Only trace levels of xylose were seen in the gpS-2 and gpS-3 fractions, where galactose was the second most abundant sugar. There were also other minor (unidentified) peaks in the chromatograms from all three preparations.

The gpS group of antigens were also extracted from petioles $24 \mathrm{~h}$ after inoculation with the avirulent $X$. campestris pv. raphani strain 1946. The pattern of JIM11 antigenicity obtained after fractionation on Sephacryl S400-HR and Bio-Rex 70 was the same as that seen in extracts from detached petioles. However, there was not enough material available for biochemical analysis.

\section{DISCUSSION}

The monoclonal antibodies MAC204 and MAC265 were originally shown to react with different epitopes on the same 95-kDa glycoprotein present in the lumen of the Rhizobium infection thread and in the intercellular spaces of uninfected pea roots (VandenBosch et al. 1989). The localization of this glycoprotein in compartments that support bacterial growth

\section{JIM 11}

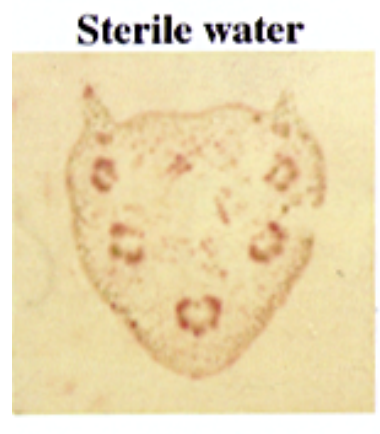

48-A

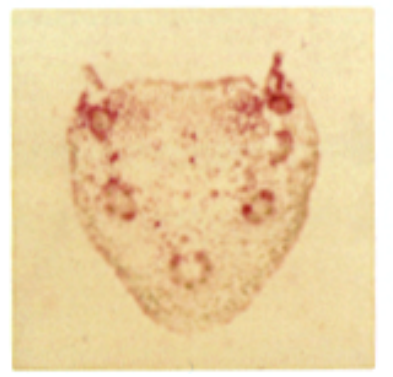

8004



$2 D 520$

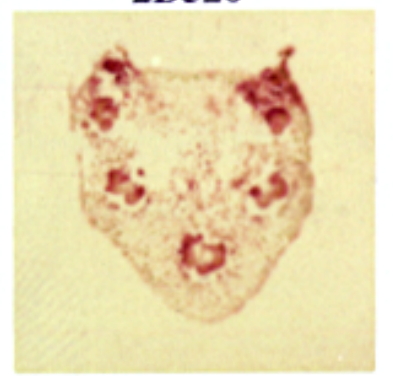

1946

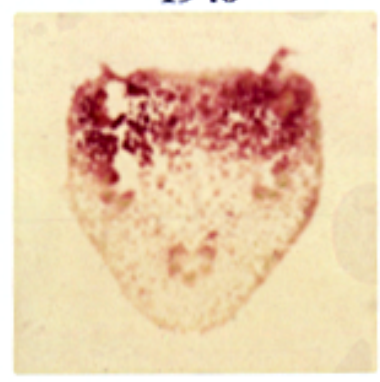

1930

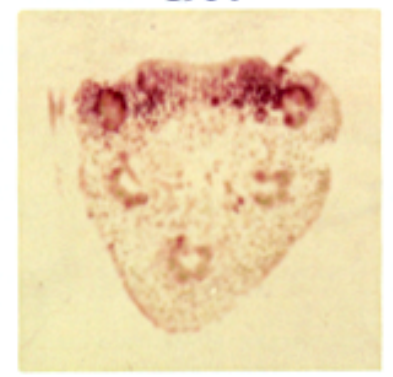

ED 8767

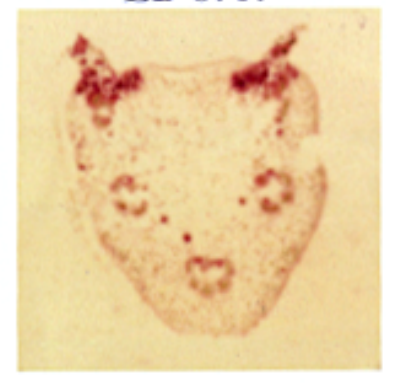

Fig. 4. Tissue prints of transverse sections of Brassica petioles $24 \mathrm{~h}$ after inoculation with different bacteria, probed with JIM11. Bacteria (and the nature of the interaction) are Xanthomonas campestris pv. campestris strains 8004 and 2D520 (both compatible), X. campestris pv. armoraciae strains 48 -A (compatible) and 1930 (incompatible), X. campestris pv. raphani strain 1946 (incompatible). Effects of inoculation with the Escherichia coli strain ED8767 are also shown. Control inoculation of petioles (with sterile water) had no effect on the pattern of antigens on tissue printing. 
led to the suggestion that it has a role in symbiosis, perhaps by promoting growth of Rhizobium. The work described in this paper had the original aim of using the same monoclonal antibodies to study whether pathogenic bacteria in compatible interactions elicited similar modifications to the plant extracellular matrix. Our results suggest that this is not the case; substantial changes in extracellular matrix glycoproteins detected with MAC204 occurred only in incompatible interactions.

In previous work (Davies et al. 1997) we described two antigens in unstressed petioles of brassicas that were recognized by MAC204: gp120, a proline-rich hydroxyproline-poor glycoprotein; and gp45, which was uncharacterized. The stresses of wounding and inoculation with avirulent bacterial pathogens both cause substantial changes in the pattern of antigens recognized by MAC204, involving the induction of two new groups of antigens, which we called gp160 and gpS. In contrast, relatively small changes in the levels of the antigens gp120 and gp45 occurred in response to these stresses. Although the chromatographic properties of the antigens induced by inoculation with avirulent bacteria are indistinguishable from those induced by wounding, we have not definitively shown that the two stresses induce the same molecular species.

The group of antigens called gpS, which were not resolved
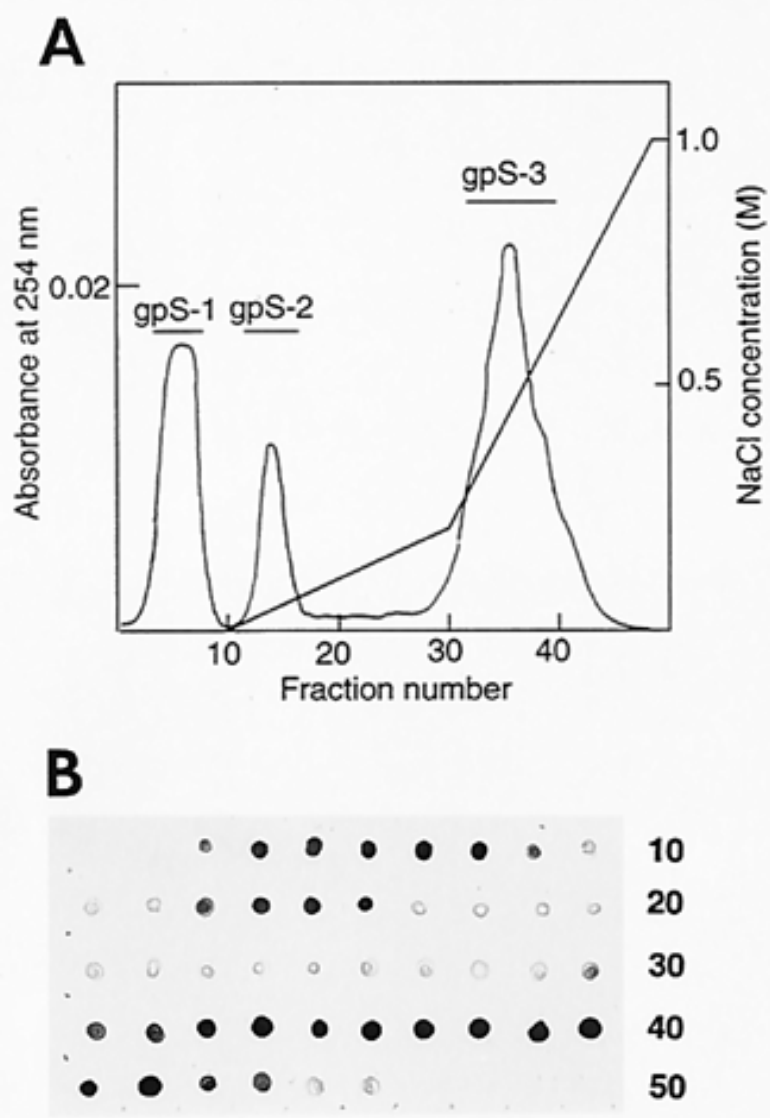

Fig. 5. Ion-exchange chromatography on Bio-Rex 70 of the crude gpS preparation. Column was equilibrated with $20 \mathrm{mM}$ Tris- $\mathrm{HCl}$ buffer $\mathrm{pH} 8$ and eluted with a biphasic gradient of $\mathrm{NaCl}$ in the same buffer. $\mathbf{A}$, Elution profile as absorbance at $254 \mathrm{~nm}$. B, Dot blot analysis of fractions with JIM11. Fraction numbers are given on the right. Fractions were pooled as indicated to give gpS-1, gpS-2, and gpS-3. by SDS-PAGE, could be resolved by ion-exchange chromatography into several fractions, each of which was recognized by both MAC204 and JIM11. The overall properties of the gpS-3 fraction (solubility in TCA, highly basic nature, amino acid and sugar composition) suggest that it is an HRGP of the extensin family (reviewed by Showalter 1993). The amino acid compositions of the gpS-1 and gpS-2 fractions are very similar to each other but differ markedly from those of either the gpS-3 fraction or the proline-rich gp120. The reaction of the gpS-3 fraction with JIM11 is consistent with the previous observations that the JIM11 epitope is carried on HRGPs such as extensins and chimeric proteins with extensin-like domains such as the solanaceous lectins (Smallwood et al. 1994). The reaction of JIM11 with the gpS-2 and gpS-3 fractions suggests that the JIM11 epitope is not restricted to (highly basic) extensin-like glycoproteins in stressed brassica petioles. As we do not know how many distinct components are present in the gpS-1 and gpS-2 fractions, we cannot tell if the JIM11 epitopes in these fractions are carried HRGPs present in minor proportions rather than on serine-rich glycoproteins with low levels of hydroxyproline. It is possible that the gpS fraction contains HRGPs of other families such as the arabinogalactan proteins (AGPs; reviewed by Showalter 1993). AGPs are known to be induced by wounding and would be soluble in TCA. AGPs are most likely to be in the gpS- 1 fraction since in general they have isoelectric points in the range of $\mathrm{pH} 2$ to 5 and hence would not stick to the ion-exchange column under the conditions used.

The large induction of extensin-like HRGPs in incompatible interactions is consistent with a large body of evidence from a number of plant-pathogen interactions that associates the induction of HRGPs with disease resistance (reviewed by Bowles 1990). A reduced response was produced with all virulent bacteria tested other than $X$. campestris pv. campestris 8004 (which produced no response). E. coli also induced a low level of JIM11 antigen. These responses to virulent bacteria were not altered when the bacteria were heat killed before inoculation. In contrast, the large response to avirulent strains required living bacteria; heat-killed avirulent strains induced a response that was markedly less than the live bacteria. These results provide some support for the concept of a generalized induction of plant defense responses by bacteria, as proposed by Jakobek and Lindgren (1993). However, if such a general mechanism does exist for the induction of HRGPs in petioles, it determines a lower level of response than that seen with metabolically active avirulent strains.

Mutants of the compatible strains that carried lesions in a number of different genes contributing to pathogenesis all produced the same level of response as the wild-type parents. This suggested that, at least in this pathosystem, the hrp gene cluster, the $h r p X$ gene, extracellular enzymes, the outer core, and $\mathrm{O}$-antigen of lipopolysaccharide and extracellular poly-

Table 3. Monosaccharide composition of glycoproteins from stressed Brassica petioles

\begin{tabular}{lccr}
\hline & \multicolumn{3}{c}{ mol\% } \\
\cline { 2 - 4 } Monosaccharide & gpS-1 & gpS-2 & gpS-3 \\
\hline Arabinose & 60.6 & 92.4 & 96.1 \\
Xylose & 20.6 & Trace & Trace \\
Galactose & 18.8 & 7.6 & 3.9 \\
\hline
\end{tabular}


saccharide do not contribute to pathogenesis by suppression of plant defense responses involving HRGP induction. This does not exclude the possibility that pathogenicity genes act to suppress other plant cell surface events such as papilla formation, as suggested for the hrp genes of $X$. campestris pv. vesicatoria by Brown et al. (1995).

It is interesting to compare our results with data on the expression of genes encoding HRGPs in wounded rape petioles obtained by Shirsat et al. (1996). These workers probed dot and Northern (RNA) blots of RNA extracted from wounded petioles with the gene extA, which encodes an extensin not normally expressed in petioles. This probe detected a strongly increased expression of several transcripts in petioles from 11 $\mathrm{h}$ after wounding. These transcripts were not present in unwounded petioles. Presumably, they encoded proline/hydroxyproline-rich (glyco)proteins that, at least in the case of extA, were not associated with the normal developmental program of petioles but were specifically wound induced. This is consistent with our own observations that wounding appears to have relatively little effect on the levels of gp120 and gp45 but causes a large induction of the novel antigens gp160 and gpS. The amino acid composition of the gpS-3 fraction (which may not be pure) is, however, different from the predicted amino acid composition of ExtA.

The stresses of wounding and inoculation with avirulent pathogens apparently do not lead to the rapid disappearance (insolubilization?) of the pre-existing antigens gp120 and gp45 in this differentiated tissue. The levels of the soluble induced antigen gpS also only slowly decrease after $24 \mathrm{~h}$ as estimated from tissue prints (H. A. Davies, unpublished). We do not know whether this loss of antigen results from turnover or insolubilization. We have not been able to detect JIM11 antigens associated with cell walls of stressed petioles by immunoelectron microscopy. The rapid disappearance of soluble PRPs and HRGPs from the cell wall of suspension culture cells as a response to avirulent bacteria or elicitors is believed to occur via rapid cross-linking catalyzed by peroxidase and requiring hydrogen peroxide generated via the oxidative burst (Bradley et al. 1992; Brisson et al. 1994). It is possible that the enzymatic capability for cross-linking is not present in healthy petioles and has to be induced, hence the absence of rapid responses. Addition of hydrogen peroxide to petiole sections does not cause insolubilization of gp120 (H. A. Davies, unpublished), supporting this contention. However, we also cannot exclude the possibility that gp120 and gp45 are incapable of undergoing a cross-linking reaction.

In the work described in this paper we have used a panel of monoclonal antibodies to characterize one aspect of the defense response of Brassica petioles; namely, the induction of soluble glycoprotein antigens. As we have only studied those antigens that can be extracted with buffers or that transfer to nitrocellulose during tissue printing, we have not directly addressed the issues of cross-linking of soluble glycoproteins or the insoluble glycoprotein antigens of the wall. The overall resistance of petioles to bacteria clearly may depend on both induction and cross-linking of cell surface glycoproteins as well as on other coordinately induced responses. A low level of induction of HRGPs is associated with several of the compatible interactions and may be induced by many bacteria. Wounding induces high levels of HRGPs. These induced glycoproteins, together with gp120 and gp45, which are already present in petioles, could potentially contribute to defense of wounded petioles against saprophytes or nonpathogens. It will be of interest to determine if pathogens such as $X$. campestris that may enter plants through wounds have evolved mechanisms to overcome these barriers.

\section{MATERIALS AND METHODS}

\section{Growth of plants, tissue dissection, and wounding.}

Plants of turnip (Brassica campestris) cv. Just Right were grown in the greenhouse with $16 \mathrm{~h}$ light at a temperature of 15 to $20^{\circ} \mathrm{C}$. Most experiments used plants between 3 and 4 weeks old. The vascular bundle, pith, and epidermis were dissected from the petiole with a scalpel as described previously (Davies et al. 1997). For wounding by detachment, leaves were cut at their base with a scalpel and were maintained with their cut ends in water for $24 \mathrm{~h}$ at $25^{\circ} \mathrm{C}$ with a 15 -h light regime. Wounding of leaves still attached to the plant was done by making lateral incisions with a scalpel or by crushing with forceps. Plants were then maintained at $25^{\circ} \mathrm{C}$ with a 15 -h light regime.

\section{Growth of bacteria and inoculation of plants.}

The bacterial strains used in this study are listed in Table 1. Xanthomonas cultures were grown in NYGB medium and $E$. coli in L broth (Daniels et al. 1984). The bacteria were harvested by centrifugation and resuspended in sterile, distilled water to a final concentration of $10^{8} \mathrm{CFU}$ per ml. These suspensions were introduced into the petiole by inoculating with a syringe (without a needle) an area of the leaf lamina that lies directly adjacent to the petiole. The inoculum was thus introduced into the pith of the petiole adjacent to the leaf lamina as demonstrated by the use of eosin dye. The plants were maintained at $25^{\circ} \mathrm{C}$ with $15 \mathrm{~h}$ of light. The number of bacterial cells in a 1-cm length of petiole was determined to be $10^{7}$ CFU by plating homogenates made in distilled water as described previously (Newman et al. 1994).

\section{Extraction of antigens from tissues.}

For most extractions, tissues were ground in a pestle and mortar with $100 \mathrm{mM}$ Tris- $\mathrm{HCl}$ buffer $\mathrm{pH} 8.5$ containing $4 \%$ (wt/vol) SDS. The homogenates were centrifuged for $5 \mathrm{~min}$ at $10,000 \times g$ and the supernatants were carefully removed. Samples for Western blotting were immediately boiled in sample loading buffer for SDS-PAGE and where necessary were stored at $-20^{\circ} \mathrm{C}$. The gpS group of antigens were extracted from the tissue with $100 \mathrm{mM}$ Tris- $\mathrm{HCl}$ buffer $\mathrm{pH} 8.5$ alone.

\section{Immunological methods.}

Extracts for Western blotting were separated by SDS-PAGE with $8 \%$ gels. Transfer of components to nitrocellulose membranes (Schleicher \& Schuell, Dassel, Germany) was done in $25 \mathrm{mM}$ Tris, $200 \mathrm{mM}$ glycine, $20 \%$ (vol/vol) methanol overnight at $4{ }^{\circ} \mathrm{C}$. Membranes for Western blots and dot blots were blocked with phosphate buffered saline containing $3 \%$ bovine serum albumin. They were probed with the monoclonal antibodies diluted to 1:25 in blocking buffer (1:100 for MAC204). The secondary antibody was alkaline phosphatase-conjugated rabbit anti-rat immunoglobulin (Sigma, Poole, UK) used at 1:15,000 dilution. Tissue-printing immunoblots were performed as described by Cassab and Varner (1987). Experi- 
ments with each bacterial strain were performed in triplicate and the whole experiment was repeated.

\section{Characterization of stress-induced JIM11 antigens (gpS).}

All manipulations were carried out at $4^{\circ} \mathrm{C}$. The presence of the antigens of interest throughout purification was assessed by dot blotting $1-\mu \mathrm{l}$ samples onto nitrocellulose and probing with JIM11.

Step 1. Extraction of JIM11 antigens. Petiole tissue from leaves stressed by detachment from 3- to 4-week-old plants $(400 \mathrm{~g})$ was homogenized in a blender with $400 \mathrm{ml}$ of 100 $\mathrm{mM}$ Tris-HCl buffer $\mathrm{pH} 8.5$ containing protease inhibitors $(5$ $\mathrm{mM}$ dithiothreitol, $10 \mathrm{mM}$ EDTA, $0.5 \mathrm{mM}$ phenylmethylsulphonyl fluoride, $10 \mu \mathrm{M}$ benzamidine hydrochloride, $5 \mu \mathrm{M}$ phenanthroline, $5 \mu \mathrm{M}$ aprotinin, $20 \mu \mathrm{M}$ leupeptin, and $15 \mu \mathrm{M}$ pepstatin A). The homogenate was passed through four layers of muslin cloth and centrifuged at 20,000 $\times g$ for $20 \mathrm{~min}$.

Step 2. Precipitation with TCA. A solution of $68 \%$ (wt/vol) TCA was added to the supernatant (with stirring) so that the final concentration of TCA was $5 \%(\mathrm{wt} / \mathrm{vol})$. This solution was left for $1 \mathrm{~h}$ at $4^{\circ} \mathrm{C}$ to precipitate contaminating proteins and other materials that were removed by centrifugation at $20,000 \times g$ for $20 \mathrm{~min}$. The supernatant was dialyzed extensively against $50 \mathrm{mM}$ Tris- $\mathrm{HCl}$ buffer $\mathrm{pH} 8.5$. The dialyzed solution was lyophilized.

Step 3. Centricon-30 filtration. The lyophilized sample was dissolved in distilled water and aliquots centrifuged in a Centricon-30 microconcentrator (Amicon, Beverly, MA), which retains the JIM11 antigens but allows the passage of green pigmented material, which was discarded. The retained sample was exchanged into $100 \mathrm{mM}$ Tris- $\mathrm{HCl}$ buffer $\mathrm{pH} 8.5$ containing $1 \mathrm{M} \mathrm{NaCl}$.

Step 4. Size exclusion chromatography on Sephacryl S400$H R$. One-milliliter samples were applied to a column $(1.5 \times 48$ $\mathrm{cm}$ ) of Sephacryl S400-HR (Sigma, Poole, U.K.) equilibrated with $100 \mathrm{mM}$ Tris- $\mathrm{HCl}$ buffer $\mathrm{pH} 8.5$ containing $1 \mathrm{M} \mathrm{NaCl}$. The column was eluted with the same buffer at a flow rate of $10 \mathrm{ml}$ per $\mathrm{h}$ and $1.2-\mathrm{ml}$ fractions were collected. The JIM11 antigens eluted within the included volume of the column; the appropriate fractions were pooled and exchanged into $20 \mathrm{mM}$ Tris- $\mathrm{HCl} \mathrm{pH} 8$ with Centricon-30 microconcentrators. This yielded the crude gpS fraction.

Step 5. Cation exchange chromatography on Bio-Rex 70. The crude gpS sample (from the size exclusion step) was further fractionated by ion-exchange chromatography on Bio-Rex 70 (Bio-Rad, Richmond, CA). The column $(1.5 \times 5 \mathrm{~cm})$ was equilibrated with $20 \mathrm{mM}$-Tris $\mathrm{HCl} \mathrm{pH} \mathrm{8.} \mathrm{Some} \mathrm{of} \mathrm{the} \mathrm{JIM11}$ antigen did not bind to the column at this $\mathrm{pH}$. This fraction was called gpS- 1 . The column was then sequentially eluted with a linear gradient of 0 to $0.2 \mathrm{M} \mathrm{NaCl}$ in $20 \mathrm{mM}$ Tris-HCL $\mathrm{pH} 8$ (total volume of $40 \mathrm{ml}$ ) followed by a linear gradient of 0.2 to $1.0 \mathrm{M} \mathrm{NaCl}$ in $20 \mathrm{mM}$ Tris-HCL pH 8 (total volume of $40 \mathrm{ml}$ ). Two-milliliter fractions were collected. Two peaks of antigenic material eluted from the column at salt concentrations between 0 and $0.1 \mathrm{M}$ and 0.25 and $0.7 \mathrm{M}$, corresponding to two peaks of absorbance at $254 \mathrm{~nm}$. These fractions (gpS-2 and gpS-3) were pooled separately and desalted in a Centricon-30 microconcentrator.

\section{Amino acid and carbohydrate analysis.}

Amino acid analysis on purified antigen preparations was performed after $6 \mathrm{~N} \mathrm{HCl}$ hydrolysis by the Microchemical Facility at the Institute of Animal Physiology and Genetics Research (Babraham, U.K.). Carbohydrate analysis was performed after hydrolysis of the samples in $2 \mathrm{M} \mathrm{TCA}$ at $100^{\circ} \mathrm{C}$ for $90 \mathrm{~min}$. Monosaccharides were converted to alditol acetate derivatives and analyzed by gas chromatography-mass spectrometry on a G1800A GCD system (Hewlett-Packard, Palo Alto, CA).

\section{ACKNOWLEDGMENTS}

The Sainsbury Laboratory is supported by a grant from the Gatsby Charitable Foundation. This work was carried out according to the provisions of the Ministry of Agriculture, Fisheries and Food license PHF1185/8(48) issued under the Plant Health (Great Britain) Order 1987 (Statutory Instrument 1758). We thank Andrew Marry for gas chromatography-mass spectrometry analysis of monosaccharide compositions.

\section{LITERATURE CITED}

Barrère, G. C., Barber, C. E., and Daniels, M. J. 1986. Molecular cloning of genes involved in the biosynthesis of the extracellular polysaccharide xanthan by Xanthomonas campestris pv. campestris. Int. J. Biol. Macromol. 8:372-374.

Bowles, D. J. 1990. Defense-related proteins in higher plants. Annu. Rev. Biochem. 59:873-907.

Bradley, D. J., Kjellbom, P., and Lamb, C. J. 1992. Elicitor- and woundinduced oxidative cross-linking of a proline-rich plant cell wall protein. Cell 70:21-30.

Brisson, L. F., Tenhaken, R., and Lamb, C. J. 1994. Functions of oxidative cross-linking of cell wall structural proteins in plant disease resistance. Plant Cell 6:1703-1712.

Brown, I., Mansfield, J., and Bonas, U. 1995. hrp genes in Xanthomonas campestris pv. vesicatoria determine ability to suppress papilla deposition in pepper mesophyll cells. Mol. Plant-Microbe Interact. 8:825836.

Cassab, G. I., and Varner, J. E. 1987. Immunocytolocalization of extensin in developing soybean seed coats by immunogold-silver staining and by tissue printing on nitrocellulose paper. J. Cell Biol. 105: 2581-2588.

Cook, A. A., Walker, J. C., and Larson, R. H. 1952. Studies on the disease cycle of black rot of crucifers. Phytopathology 42:162-167.

Daniels, M. J., Barber, C. E., Turner, P. C., Sawczyc, M. K., Byrde, R. J. W., and Fielding, A. H. 1984. Cloning of genes involved in pathogenicity of Xanthomonas campestris pv. campestris using the broad host range cosmid pLAFR1. EMBO J. 3:3323-3328.

Davies, H. A. 1996. A family of glycoproteins from petioles of Brassica campestris with potential roles in plant development and stress responses. Ph.D. thesis. University of East Anglia, Norwich, U.K.

Davies, H. A., Daniels, M. J., and Dow, J. M. 1997. A novel proline-rich glycoprotein associated with the extracellular matrix of vascular bundles of Brassica petioles. Planta 202:28-35.

Dow, J. M., Osbourn, A. E., Wilson, T. J. G., and Daniels, M. J. 1995. A locus determining pathogenicity of Xanthomonas campestris is involved in lipopolysaccharide biosynthesis. Mol. Plant-Microbe Interact. 8:768-777.

Dow, J. M., Scofield, G., Trafford, K., Turner, P. C., and Daniels, M. J. 1987. A gene cluster in Xanthomonas campestris pv. campestris required for pathogenicity controls the excretion of polygalacturonate lyase and other enzymes. Physiol. Mol. Plant Pathol. 31:261-271

Esquerré-Tugayé, M. T., Lafitte, C., Mazau, D., Toppan, A., and Touzé, A. 1979. Cell surfaces in plant-microorganism interactions. II Evidence for the accumulation of hydroxyproline-rich glycoproteins in the cell wall of diseased plants as a defense mechanism. Plant Physiol. 64:320-326.

Jakobek, J. L., and Lindgren, P. B. 1993. Generalized induction of defense responses in bean is not correlated with the induction of the hypersensitive reaction. Plant Cell 5:49-56.

Jakobek, J. L., Smith, J. A., and Lindgren, P. B. 1993. Suppression of bean defense responses by Pseudomonas syringae. Plant Cell 5:57-63.

Kamoun, S., Kamdar, H. V., Tola, E., and Kado, C. I. 1992. Incompatible 
interactions between crucifers and Xanthomonas campestris involve a vascular hypersensitive response: Role of the hrpX locus. Mol. PlantMicrobe Interact. 5:22-33

Leach, J. E., Cantrell, M. A., and Sequeira, L. 1982. Hydroxyprolinerich bacterial agglutinin from potato. Plant Physiol. 70:1353-1358.

Liddle, S. A. 1992. Strategies for studying pathogenicity genes of Xanthomonas campestris pv. campestris. Ph.D. thesis. University of East Anglia, Norwich, U.K.

Mellon, J. E., and Helgeson, J. P. 1982. Interaction of a hydroxyprolinerich glycoprotein from tobacco callus with potential pathogens. Plant Physiol. 70:401-405.

Millar, D. J., Slabas, A. R., Sidebottom, C., Smith, C. G., Allen, A. K. and Bolwell, G. P. 1992. A major stress-inducible $\mathrm{M}_{\mathrm{R}}-42000$ wall glycoprotein of French bean (Phaseolus vulgaris L.) Planta 187:176-184.

Murray, N. E., Brammer, W. J., and Murray, K. 1977. Lambdoid phages that simplify the recovery of in vitro recombinants. Mol. Gen. Genet. 150:53-61.

Newman, M.-A., Conrads-Strauch, J., Scofield, G., Daniels, M. J., and Dow, J. M. 1994. Defense-related gene induction in Brassica campestris in response to defined mutants of Xanthomonas campestris with altered pathogenicity. Mol. Plant-Microbe Interact. 7:553-563.

Palva, T. K., Holmström, K.-O., Heino, P., and Palva, T. P. 1993. Induction of plant defense response by exoenzymes of Erwinia carotovora subsp. carotovora. Mol. Plant-Microbe Interact. 6:190-196.

Shaw, J. J., and Kado, C. I. 1988. Whole plant wound inoculation for consistent reproduction of black rot of crucifers. Phytopathology 78: 981-986.
Shaw, J. J., Settles, L. G., and Kado, C. I. 1988. Transposon Tn4431 mutagenesis of Xanthomonas campestris pv. campestris: Characterization of a nonpathogenic mutant and cloning of a locus for pathogenicity. Mol. Plant-Microbe Interact. 1:39-45.

Shirsat, A. H., Wieczorek, D., and Kozbial, P. 1996. A gene for Brassica napus extensin is differentially expressed on wounding. Plant Mol. Biol. 30:1291-1300.

Showalter, A. M. 1993. Structure and function of plant cell wall proteins. Plant Cell 5:9-23.

Showalter, A. M., Bell, J. N., Cramer, C. L., Bailey, J. A., Varner, J. E., and Lamb, C. J. 1985. Accumulation of hydroxyproline-rich glycoprotein mRNAs in response to fungal elicitor and infection. Proc. Natl. Acad. Sci. USA 82:6551-6555.

Smallwood, M., Beven, A., Donovan, N., Neill, S. J., Peart, J., Roberts, K., and Knox, J. P. 1994. Localization of cell wall proteins in relation to the developmental anatomy of the carrot root apex. Plant J. 5:237246

Swords, K. M. M., and Staehelin, L. A. 1993. Complementary immunolocalization patterns of cell wall hydroxyproline-rich glycoproteins studied with the use of antibodies directed against different carbohydrate epitopes. Plant Physiol. 102:891-901.

VandenBosch, K. A., Bradley, D. J., Perotto, S., Butcher, G. W., and Brewin, N. J. 1989. Common components of the infection thread matrix and the intercellular space identified by immunochemical analysis of pea nodules and uninfected roots. EMBO J. 8:335-342.

Williams, P. H. 1980. Black rot: A continuing threat to world crucifers. Plant Dis. 64:736-742. 